\title{
Cerebro-placental ratio as a prognostic factor of fetal outcome in women with hypertensive disorders complicating pregnancy during third trimester
}

\author{
Sahana K. ${ }^{1}$, Suma K. B. ${ }^{1}$, Nischay R. ${ }^{2 *}$ \\ ${ }^{1}$ Department of Obstetrics and Gynecology, Medical College, Mysore, Karnataka, India \\ ${ }^{2}$ Department of Gastroenterology, Shantaveri Gopala Gowda Hospital, Mysore, Karnataka, India
}

Received: 21 July 2020

Accepted: 04 September 2020

\author{
*Correspondence: \\ Dr. Nischay R., \\ E-mail: nischay.mmc@gmail.com
}

Copyright: ( $)$ the author(s), publisher and licensee Medip Academy. This is an open-access article distributed under the terms of the Creative Commons Attribution Non-Commercial License, which permits unrestricted non-commercial use, distribution, and reproduction in any medium, provided the original work is properly cited.

\begin{abstract}
Background: CPR is emerging as an important predictor of adverse pregnancy outcome and helps in management of high risk pregnancy. Therefore we undertook the study to find the correlation of CPR with perinatal outcomes in women with hypertensive disorder complicating during third trimester.

Methods: 128 patients with hypertensive disorder of pregnancy, $\geq 32$ weeks of singleton gestation, were randomly selected during their hospital visit. They were subjected to USG Doppler study to calculate MCA/UA pulsatility index-CPR. The CPR $<1$ was considered abnormal and $>1$ as normal. These results were compared with the perinatal outcome and adverse fetal outcome.

Results: The present study revealed that the incidence of adverse outcomes like Apgar score $<7$ (36.5\%), still birth (15.9\%), NICU admission (69.8\%) and LBW i.e. <2500 gm (68.3\%) were significantly higher in abnormal CPR than normal CPR.

Conclusions: Abnormal CPR is valuable in predicting the outcome of hypertensive disorders in pregnancy. CPR is an easy procedure which can be included in the routine antenatal sonographic evaluation to predict poor perinatal outcome and to detect or recognize those fetuses at risk.
\end{abstract}

Keywords: Cerebro placental ratio, Hypertensive disorders of pregnancy, Middle cerebral artery, Umbilical artery

\section{INTRODUCTION}

Hypertensive disorders represent the most common maternal and perinatal complication of pregnancy. It has been reported that the incidence of this disorder is between 5 and 10 percent. Hypertensive disorders associated with pregnancy along with haemorrhage and infection form a deadly triad that contributes greatly to maternal as well as perinatal morbidity and mortality. ${ }^{1,2}$

Preeclampsia is associated with increased vascular resistance and decreased uteroplacental perfusion resulting in increased incidence of fetal hypoxia. In such condition, fetal modifications occur in retort to non- performance of the maternal-placental nutrients supply so as to meet the foetal demands. ${ }^{3,4}$

In recent decades, routine antenatal ultrasonography is commonly used in assessment of anthropometric measurement of umbilical cord and placenta and also to detect the intrauterine growth retardation (IUGR) and congenital anomalies. Yet women with high risk pregnancies like hypertensive disorder of pregnancy and diabetes mellitus were showing the increase incidence of maternal and fetal morbidity. Various biochemical tests used in screening of high risk population for preeclampsia have lower positive predictive values, high cost and less patient compliance. ${ }^{5}$ 
Doppler sonography especially cerebro-placental ratio (CPR) is a rapid non-invasive test that provides valuable information about hemodynamic status of the fetus and is an efficient diagnostic test to evaluate blood flow alteration in placenta-umbilical and feto-cerebral circulation. The CPR is calculated by dividing the Doppler pulsatility index from the middle cerebral artery (MCA) into the umbilical artery (UA). CPR is emerging as an important predictor of adverse pregnancy outcome and helps in management of high risk pregnancy. ${ }^{6,7}$ Therefore we undertook the study to find the correlation of CPR with perinatal outcomes in women with hypertensive disorder complicating during third trimester.

\section{METHODS}

This cross-sectional study was conducted among 128 pregnant women who underwent a routine antenatal sonogram at the Department of Radiodiagnosis, JSS medical college, Mysuru, Karnataka, India, during the study period November 2015 to July 2017. The study was approved by the Institutional Ethical Committee and written informed consent was obtained from the participants.

\section{Inclusion criteria}

Our inclusion criteria were singleton pregnant women with hypertensive disorder of pregnancy and gestational age at the time of study $\geq 28$ weeks.

\section{Exclusion criteria}

We excluded pregnancies completed with co-morbid conditions like gestational diabetes, IUGR, oligohydramnios, polyhydramnios and intrauterine death (IUD).

About 128 antenatal women were selected after consideration of inclusion and exclusion criteria, their preliminary data were recorded and were subjected to ultrasound scan for fetal anthropometric parameters, fetal and placental position, fetal age and heart rate, umbilical artery pulsatility index (UI), middle cerebral artery pulsatility index (MI). CPR will be calculated from Middle cerebral artery pulsatility index and Umbilical artery pulsatility index.

A CPR was defined as normal and abnormal when its ratio was $>1.0$ and $<1.0$ respectively. Based on the above statement, cases were divided into normal group $(\mathrm{CPR}>1.0)$, and abnormal group $(\mathrm{CPR}<1.0)$. Follow up with respect to perinatal outcome and to detect the fetuses at risk.

The mean and standard deviation of MCA PI and UA PI were calculated for different gestational age groups. The data obtained were statistically analysed using SPSS software version 20.0. Association between cerebroplacental ratio and other categorical variables were analysed using chi-square test. Pearson Correlation coefficient was used to show correlation between cerebro-placental ratio and other quantitative variables like birth weight.

\section{RESULTS}

Total one hundred and twenty eight pregnant women were included in this study. The mean $\pm \mathrm{SD}$ of maternal age was $24.74 \pm 4.08$ years, ranging from $18-37$ years. The mean $\pm \mathrm{SD}$ of gestational age during delivery was $36.78 \pm 2.46$ weeks, ranging from $32-41$ weeks. The mean birth weight was $2.44 \mathrm{~kg}$ ( $\mathrm{SD}=0.74)$, ranging from 0.60 to $3.60 \mathrm{~kg}$. Table 1 shows the maternal and perinatal characteristics of study population.

Table 1: Maternal and perinatal characteristics of study population $(n=128)$.

\begin{tabular}{|ll|}
\hline Characteristics & n (\%) \\
\hline Parity & $82(64.1 \%)$ \\
\hline Primipara & $46(35.9 \%)$ \\
\hline Multipara & \\
\hline HTN disorder in pregnancy & $26(20.33 \%)$ \\
\hline Eclampsia & $91(71.1 \%)$ \\
\hline Pre-eclampsia & $11(08.6 \%)$ \\
\hline Gestational HTN & \\
\hline Delivery & $26(20.3 \%)$ \\
\hline Normal vaginal delivery & $102(79.7 \%)$ \\
\hline LSCS & $118(92.2 \%)$ \\
\hline Fetal outcome & $10(07.8 \%)$ \\
\hline Live birth & \\
\hline Still birth & $28(21.8 \%)$ \\
\hline Apgar score at 5 minutes & $100(78.2 \%)$ \\
\hline$\leq 7$ & \\
\hline$>7$ & $79(61.7 \%)$ \\
\hline Admission to NICU & $49(38.3 \%)$ \\
\hline Yes & \\
\hline No & \\
\hline
\end{tabular}

Table 2: Descriptive statistics of MCA pulsatility, UA pulsatility based on gestational age (by USG).

\begin{tabular}{|llllll|}
\hline $\begin{array}{l}\text { Gestational } \\
\text { age }\end{array}$ & $\begin{array}{l}\text { No. of } \\
\text { cases }\end{array}$ & Mean & SD & Mean & SD \\
\hline $\mathbf{2 8}$ & 03 & 0.55 & 0.78 & 0.90 & 1.27 \\
\hline $\mathbf{2 9}$ & 02 & 1.20 & 0.14 & 1.85 & 1.06 \\
\hline $\mathbf{3 0}$ & 06 & 0.86 & 0.67 & 0.99 & 0.84 \\
\hline $\mathbf{3 1}$ & 04 & 1.00 & 0.69 & 1.15 & 0.85 \\
\hline $\mathbf{3 2}$ & 09 & 1.23 & 0.50 & 1.36 & 0.72 \\
\hline $\mathbf{3 3}$ & 08 & 0.91 & 0.58 & 1.28 & 0.88 \\
\hline $\mathbf{3 4}$ & 13 & 1.23 & 1.55 & 1.66 & 0.34 \\
\hline $\mathbf{3 5}$ & 08 & 1.27 & 0.22 & 1.37 & 0.34 \\
\hline $\mathbf{3 6}$ & 24 & 1.31 & 0.20 & 1.34 & 0.35 \\
\hline $\mathbf{3 7}$ & 15 & 1.28 & 0.26 & 1.54 & 0.37 \\
\hline $\mathbf{3 8}$ & 18 & 1.29 & 0.40 & 1.38 & 0.48 \\
\hline $\mathbf{3 9}$ & 10 & 1.44 & 0.24 & 1.26 & 0.22 \\
\hline $\mathbf{4 0}$ & 08 & 1.44 & 0.97 & 1.09 & 0.08 \\
\hline Total & 128 & 1.23 & 0.40 & 1.35 & 0.53 \\
\hline
\end{tabular}


Table 2 shows descriptive statistics of MCA pulsatility index, UA pulsatility index based on gestational age (by USG). The middle cerebral artery pulsatility index (MCA PI) had a mean value of 1.22 , with the scores ranging in between 0 to 1,96 ; The Umbilical artery (UA) pulsatility index had mean value of 1.34 (range $0-2.6$ ).

Table 3: Perinatal outcome characteristics based on cerebro-placental ratio.

\begin{tabular}{|c|c|c|c|}
\hline Variables & $\begin{array}{l}\text { Abnormal } \\
\text { CPR }(n=63)\end{array}$ & $\begin{array}{l}\text { Normal } \\
\text { CPR }(n=65)\end{array}$ & P value \\
\hline \multicolumn{4}{|c|}{ Mode of delivery [n (\%)] } \\
\hline NVD & $14(22.2 \%)$ & $12(18.5 \%)$ & \multirow{2}{*}{$\begin{array}{l}0.597 \\
(\mathrm{NS})\end{array}$} \\
\hline LSCS & $49(77.8 \%)$ & $53(81.5 \%)$ & \\
\hline \multicolumn{4}{|c|}{ Apgar score [n (\%)] } \\
\hline$<7$ & $23(36.5 \%)$ & $05(7.7 \%)$ & \multirow{2}{*}{$\begin{array}{l}0.000 \\
(\mathrm{SIG})\end{array}$} \\
\hline$>7$ & $40(63.5 \%)$ & $60(92.3 \%)$ & \\
\hline \multicolumn{4}{|c|}{ Fetal outcome [n (\%)] } \\
\hline Alive & $53(84.1 \%)$ & $65(100.0 \%)$ & \multirow{2}{*}{$\begin{array}{l}0.001 \\
(\mathrm{SIG})\end{array}$} \\
\hline Still birth & $10(15.9 \%)$ & $0(0 \%)$ & \\
\hline \multicolumn{4}{|c|}{ NICU admission [n (\%)] } \\
\hline Yes & $44(69.8 \%)$ & $35(53.8 \%)$ & \multirow{2}{*}{$\begin{array}{l}0.063 \\
(\mathrm{NS})\end{array}$} \\
\hline No & $19(30.2 \%)$ & $30(46.2 \%)$ & \\
\hline \multicolumn{4}{|c|}{ Birth weight [n (\%)] } \\
\hline$<2500 \mathrm{gm}$ & $43(68.3 \%)$ & $19(58.7 \%)$ & \multirow{2}{*}{$\begin{array}{l}0.000 \\
(\mathrm{SIG})\end{array}$} \\
\hline$>2500 \mathrm{gm}$ & $20(31.7 \%)$ & $46(70.8 \%)$ & \\
\hline \multicolumn{4}{|c|}{ Gestational age at the time of delivery [n (\%)] } \\
\hline$\leq 37$ weeks & $38(60.3 \%)$ & $30(46.2 \%)$ & \multirow{2}{*}{$\begin{array}{l}0.108 \\
(\mathrm{NS})\end{array}$} \\
\hline$>37$ weeks & $25(39.7 \%)$ & $35(53.8 \%)$ & \\
\hline
\end{tabular}

Table 4: Correlation between cerebro-placental ratio and various other variables in the Study $(\mathrm{N}=128)$.

\begin{tabular}{|lll|}
\hline Parameter & $\begin{array}{l}\text { Correlation } \\
\text { coefficient }\end{array}$ & P value \\
\hline $\begin{array}{l}\text { Gestational age at the } \\
\text { time of delivery }\end{array}$ & 0.315 & $<0.0001$ \\
\hline Gestational age (USG) & 0.432 & $<0.0001$ \\
\hline Birth weight & 0.565 & $<0.0001$ \\
\hline Apgar score at 5 minutes & 0.659 & $<0.0001$ \\
\hline
\end{tabular}

The cerebro-placental ratio (CPR) was calculated and showed a mean value of 0.92 , ranging from 0 to 1.63 ; the value below 1.0 was considered as abnormal, and value above 1.0 was considered as normal. The adverse perinatal outcomes are LSCS, Apgar score $<7$ at 5 minutes, still birth, preterm delivery, NICU admission, and low birth weight (LBW $<2500 \mathrm{gm}$ ) was observed in both the normal CPR and abnormal CPR. Table 3 shows the perinatal outcome characteristics based on the cerebro-placental ratio. Table 4 shows the correlation between CPR and other variables in the present study. The study population showed significant correlation between gestational age (both at the time of delivery and USG), birth weight, Apgar score at $5 \mathrm{~min}$ and cerebro placental ratio values. All the values were statistically significant $(\mathrm{p}<0.01)$.

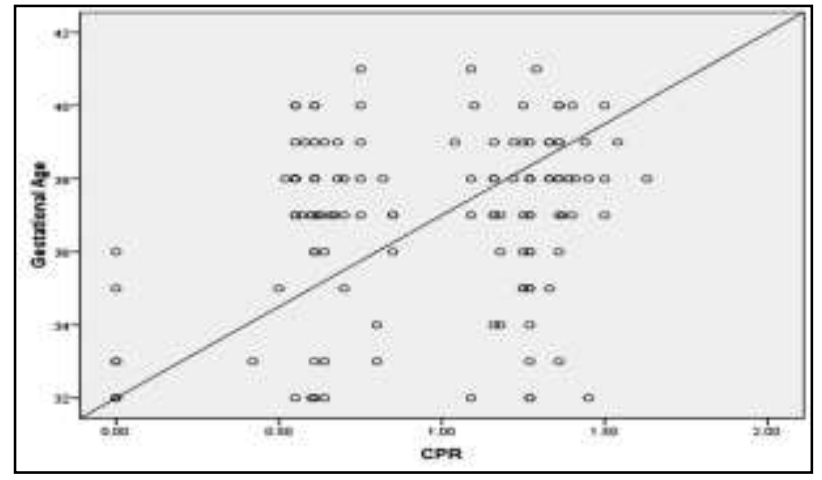

Figure 1: Scatter diagram of CPR with gestational age (GA) at the time of delivery.

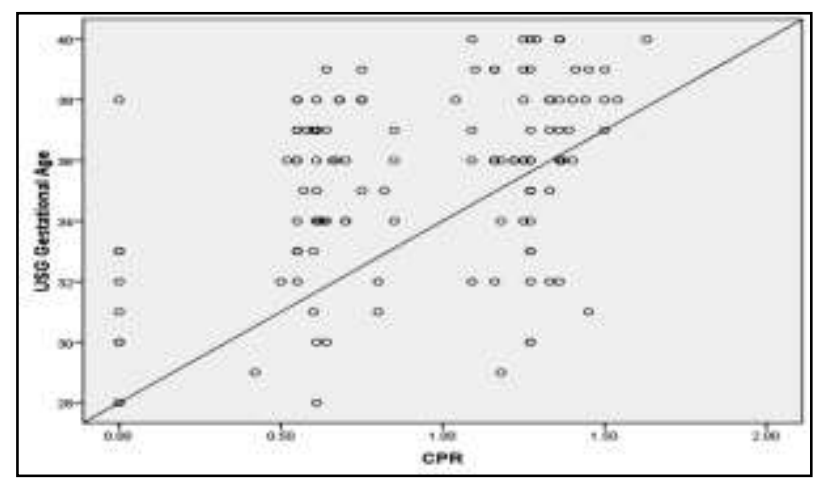

Figure 2: Scatter diagram of CPR with gestational age (as per USG).

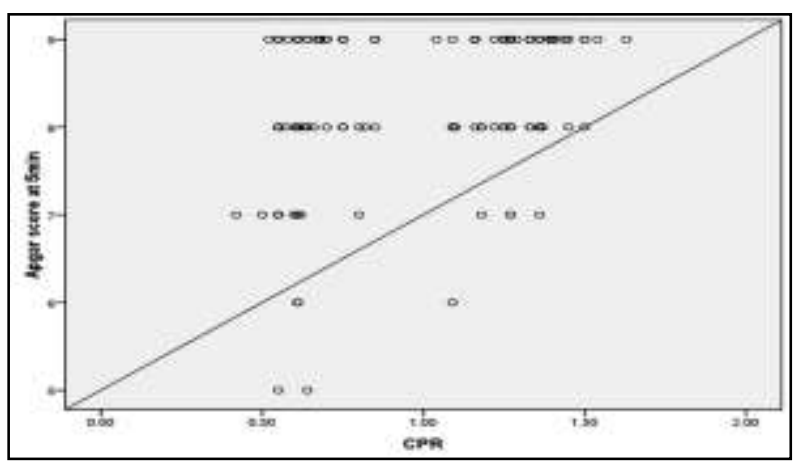

Figure 3: Scatter diagram of CPR with Apgar score at 5 minutes.

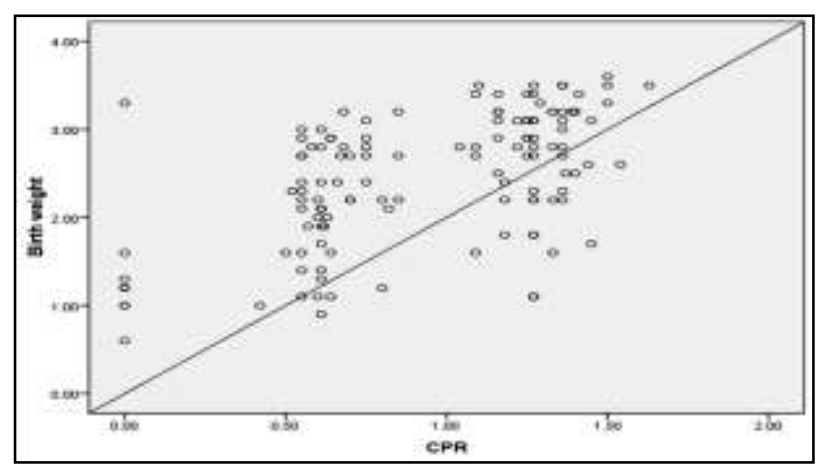

Figure 4: Scatter diagram of CPR with birth weight. 


\section{DISCUSSION}

The primary goal of every obstetrician is to identify the pregnancies at risk and to prevent them from the perinatal morbidity and mortality. Every life in the earth has authority to born healthy both physically and mentally.

Doppler index of umbilical artery and middle cerebral artery especially pulsatility index was measured based on gestational age during third trimester. It is very difficult to use single cut off value for pulsatility index after 30 weeks, whereas CPR is very realizable to use as single cut off value after 30 weeks because cerebral-umbilical Doppler ratio does not vary significantly between $30^{\text {th }}$ and $40^{\text {th }}$ weeks as reported by Waldimiroff et al. ${ }^{8}$ This statement is in agreement with Arbeille et al. ${ }^{9} \mathrm{He}$ suggested 1 as the cut off value and all values below 1 were considered abnormal. We classified our cases based on Arbeille et al. ${ }^{9}$

In this present study it was shown that majority of the study population were primigravida. Among the pregnancy related hypertension, pre-eclampsia was the most common cause followed by eclampsia and gestational hypertension. The present study revealed that the incidence of adverse outcomes like Apgar score <7 (36.5\%), still birth (15.9\%), NICU admission (69.8\%) and LBW i.e. $<2500$ gm $(68.3 \%)$ were significantly higher in abnormal CPR than normal CPR.

Our observation is in concordance with Kant et al, who conducted the case control study to measure the CPR in normal and high risk pregnant women. Kant et al (2016) reported a high correlation between the abnormal CPR with caesarean section and NICU admission. ${ }^{10}$ In another study by Dagade et al clearly described an association of abnormal CPR with low birth weight, caesarean section, NICU admission and intrauterine death. ${ }^{11}$

The middle cerebral artery pulsatility index (MCA PI) had a mean value of 1.22 (range 0 to 1.96). The Umbilical artery (UA) pulsatility index had mean value of 1.34 (range 0-2.6). The MCA PI is found to be significant independent predictive value of LBW. This observation was in accordance with observation of Lam et al. ${ }^{12}$

A statistically significant positive correlation was observed between CPR and gestational age at the time of delivery $\left(\mathrm{r}^{2}=0.315, \mathrm{P}<0.0001\right)$, gestational age by USG $\left(r^{2}=0.432, P<0.0001\right)$, birth weight $\left(r^{2}=0.565, P<0.0001\right)$ and Apgar score at 5 minutes $\left(\mathrm{r}^{2}=0.659 \mathrm{P}<0.0001\right)$. In this study abnormal CPR had highest sensitivity $(68.3 \%)$ for predicting low birth weight, $69.8 \%$ for NICU admission, and $77.8 \%$ for caesarean section and had highest specificity (100\%) for predicting still birth, $70.8 \%$ for low birth weight. The sensitivity was comparable with that of Gramellini et al, Fong et al and Srilakshmi which accounts for $24 \%, 72.4 \%$ and $83.3 \%$ respectively. ${ }^{13-15}$
Literature review reveals that the appropriate for gestational age (AGA) fetuses with a birth weight above the $10^{\text {th }}$ percentile had the higher prevalence of adverse outcome.

Hence it could be justified that, primary care should be initiated for identifying fetal hypoxia instead of small for fetus where adverse outcome is due to consequence of placental impairment. Further screening should focus on the detection of pregnancies with low CPR rather than those with low estimated fetal weight. ${ }^{16}$

The major limitation of our study was the low sample size. We suggest further studies with bigger sample sizes to validate the results of the present study.

\section{CONCLUSION}

The results of the present study revealed the relationship between cerebro-placental ratio and hypertensive disorder of pregnancies. CPR is an easy procedure which can be included in the routine antenatal sonographic evaluation to predict poor perinatal outcome and to detect or recognize those foetuses at risk irrespective of the findings of the individual values of MCA and UA. Such pregnancies should be closely followed up for the successful perinatal outcome.

Funding: No funding sources

Conflict of interest: None declared

Ethical approval: The study was approved by the Institutional Ethics Committee

\section{REFERENCES}

1. Aarthy GN, Study of relationship between plasma homocysteine levels and gestational hypertension (Dissertation). Coimbatore, Coimbatore Medical College, Tamilnadu Dr. M.G.R Medical University. 2012.

2. Jain K, Kavi V, Rahuveer CV, Sinha R. Placental pathology in pregnancy induced hypertension (PIH) with or without intrauterine growth retardation; Indian J Pathol microbial. 2007;50(3):533-7.

3. Özeren M, Dinç H, Ekmen Ü, Senekayli C, Aydemir V. Umbilical and middle cerebral artery Doppler indices in patients with preeclampsia. Eur J Obstet Gynecol Reprod Biol. 1999;82(1):11-6.

4. Bimpong S. Quantitative evaluation of umbilical cord and placental indices and pregnancy outcome (Doctoral dissertation). Kumasi, Kwame Nkrumah University of Science and Technology. 2012.

5. Patil AS. Role of uterine artery Doppler at 12 to 16 weeks of gestation in prediction of pre-eclampsia an observational study. (Doctoral dissertation). Rajiv Gandhi University of Health Sciences, Bangalore. 2014.

6. Brar HS, Horenstein J, Medearis AL, Platt LD, Phelan JP, Paul RH. Cerebral, umbilical, and uterine 
resistance using Doppler velocimetry in postterm pregnancy. J Ultrasound Med. 1989;8(4):187-91.

7. Barati M, Jafarei RM, Aberoumand S, Shojaei K, Jefride Y, Masihi S, et al. Factors influencing the cerebroplacental ratio in non-severe small for gestational age fetuses at the age of 28-38 weeks of gestation. Jentashapir J Health Res. 2019;10 (1).

8. Wladimiroff JW, Degani S, Noordam MJ, Tonge HM. Cerebral and umbilical arterial blood flow velocity waveforms in normal and growth-retarded pregnancies. Obstet Gynecol. 1987;69(5):705-9.

9. Arbeille PH, Roncin A, Berson M, Patat F, Pourcelot L. Exploration of the fetal cerebral blood flow by duplex Doppler- linear array system in normal and pathological pregnancies. Ultrasound Med Biol. 1987;13(6):329-37.

10. Kant A, Seth N, Rastogi D. Comparison of outcome of normal and high-risk pregnancies based upon cerebroplacental ratio assessed by Doppler studies. J Obstet Gynecol India. 2017;67(3):173-7.

11. Dagade S, Hangekar P. Importance of cerebroplacental ratio in prediction of adverse perinatal outcome in unselected pregnancies of western Maharashtra population. Indian J Basic Appl Med Res. 2018;7(3):41-8.

12. Lam H, Leung WC, Lee CP, Lao TT. The use of fetal Doppler cerebroplacental blood flow and amniotic fluid volume measurement in the surveillance of postdated pregnancies. Acta Obstet Gynecol Scand. 2005;84:844-8.

13. Gramellini D, Folli MC, Raboni S, Vadora E, Merialdi A. Cerebral-umbilical Doppler ratio as a predictor of adverse perinatal outcome. Obstet Gynecol. 1992;79(3):416-20.

14. Fong KW, Ohlsson A, Hannah ME, Grisaru S, Kingdom J, Cohen H, et al. Prediction of perinatal outcome in fetuses suspected to have intrauterine growth restriction: Doppler US study of fetal cerebral, renal, and umbilical arteries. Radiology. 1999;213(3):681-9.

15. Srilakshmi KN. Study of triple vessel wave pattern by Doppler studies in low risk and high risk pregnancies and perinatal outcome (Doctoral dissertation). Rajiv Gandhi University of Health Sciences, Bangalore. 2013.

16. Yuvabalakumaran G, Ranjeeta K. Prospective study of role of cerebro placental ratio in predicting perinatal outcome in appropriate for gestation age (AGA) babies at 35-37 weeks. MedPulse Int J Radiol. 2019;11(2):55-60.

Cite this article as: Sahana K, Suma KB, Nischay R. Cerebro-placental ratio as a prognostic factor of fetal outcome in women with hypertensive disorders complicating pregnancy during third trimester. Int $\mathbf{J}$ Reprod Contracept Obstet Gynecol 2020;9:4109-13. 